\title{
THỰC TRANG BIẾN CHỨNG TRONG LỌC MÁU VÀ KẾT QUẢ CHĂM SÓC NGƯỜI BỆNH SUY THẬN MẠN GIAI ĐOẠN CUỐI CÓ LỌC MÁU CHU KỲ TẠI BÊ̂NH VIÊ̂N ĐA KHOA CÀ MAU
}

\section{TÓM TẮT}

Nghiên cứu mô tả tiến cứu thực hiện trên 384 người bệnh tại Bệnh viện đa khoa Cà Mau từ tháng 11/2020 đến 05/2021 trên bênh nhân suy thân mạn giai đoạn cuối có lọc máu chu kỳ tại Khoa Thận lọc máu - Bênh viên đa khoa Cà Mau bểnh viên đa khoa Cà Mau. Mục tiều (1) Xác định tỷ lệ biến chứng trong loc máu và yếu tố liên quan (2) Đánh giá kết quả chăm sóc người bệnh suy thận mạn giai đoạn cuối có loc máu chu kỳ tại bệnh viện đa khoa Cà Mau. Số liệu thu thập được là bệnh án nghiên cứu về biến chứng của người bệnh trong buổi lọc máu chu kỳ và chăm sóc, tư vấn cho người bệnh. Kết quả: nam cao hơn nữ. Chiếm tỷ lệ cao nhất ở nhóm tuổi 36-59, thấp nhất thuộc nhóm tuổi 18-35. Hâuu hết là hộ nghèo chiếm $84,4 \%$, tiếp đến hộ nghèo $(10,9 \%)$. Hầu hết NB bị bệnh lớn hơn 3 năm chiếm 94,8\%, dưới 3 năm chỉ có $5,2 \%$. Có biến chứng tụt huyết áp: chiếm tỷ lệ cao nhất vào giờ thứ $3(20,8 \%)$, tiếp đến giờ thứ 2 $(3,9 \%)$, giớ 1 không có $(0,0 \%)$, sau lọc là $2,6 \%$. Cả chu kỳ có biến chứng tụt huyết áp chiếm $27,3 \%$. Có hỏng FAV trong lọc máu chỉ chiếm 0,3 ở giờ thứ 3 và sau loc chiếm 6,3\%, tính cả chu kỳ chiếm 6,5\%. Tỷ lê có biến chứng trong buổi lọc máu chu kỳ chiếm $37 \%$ và kèm theo các triệu chứng của biến chứng như da ẩm lạnh, vã mồ hôi: vào giờ thứ 3 và sau lọc đồng chiếm 19,5\%, chuôtt rút: tỷ lệ cao nhất vào giờ thứ 3 $(20,1 \%)$, sau lọc chiếm $6,5 \%$. Buồn nôn, nôn: chỉ có ở giờ thứ $3(15,6 \%)$ và sau lọc $(1,6 \%)$, hoa mắt, chóng mặt: chiếm nhiếu ở giờ thứ $3(19,5 \%)$ và sau lọc $(3,1 \%)$, đau bụng, đi ngoài: giờ 1 và 2 đồng chiếm $3,6 \%$, giờ $3(3,4 \%)$, và sau lọc $(3,9 \%)$

Tư khóa: Biến chứng, lọc máu chu kỳ, lâm sàng, cận lâm sàng, chăm sóc, tư vấn, bệnh nhân

\section{SUMMARY \\ SITUATION OF COMPLICATIONS IN DIALYSIS AND RESULTS OF CARE FOR PATIENTS WITH END-STAGE CHRONIC RENAL FAILURE UNDERGOING DIALYSIS AT CA MAU GENERAL HOSPITAL}

A prospective descriptive study performed on 384 patients at Ca Mau General Hospital from November 2020 to May 2021 on patients with end stage chronic renal failure undergoing dialysis at the Department of Nephrology and Dialysis - Hospital. Ca Mau General

\footnotetext{
${ }^{1}$ Bênh viện $Đ K$ Cà Mau

${ }^{2}$ Trường $Đ H$ Thăng Long

Chịu trách nhiệm chính: Lê Thị Bình

Email: lethibinh1818@gamail.com

Ngày nhận bài: 17.5.2021

Ngày phản biên khoa hoc: 2.7.2021

Ngày duyệt bài: 16.7.2021
}

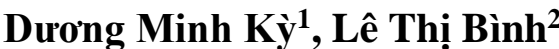

Hospital, Ca Mau General Hospital. Objectives (1) Determine the rate of complications in dialysis and related factors (2) Evaluate the outcome of care for patients with end-stage renal failure undergoing dialysis at Ca Mau General Hospital. The collected data are medical records of the patient's complications during the dialysis session and care and counseling for the patient. Result: men are taller than women. The highest rate is in the 36-59 age group, the lowest is in the 18-35 age group. Most are poor households accounting for $84.4 \%$, followed by poor households $(10.9 \%)$. Most of the patients with disease older than 3 years accounted for $94.8 \%$, less than 3 years only $5.2 \%$. There is a complication of hypotension: the highest rate is in the 3rd hour $(20.8 \%)$, followed by the 2 nd hour $(3.9 \%)$, no less $(0.0 \%)$, after the 2 nd hour of filtration. $6 \%$. The whole cycle had complications of hypotension, accounting for $27.3 \%$. FAV failure in dialysis only accounted for 0.3 at the 3rd hour and after dialysis accounted for $6.3 \%$, including the cycle accounting for $6.5 \%$. The rate of complications in the dialysis session accounted for $37 \%$ and accompanied by symptoms of complications such as cold moist skin, sweating: at the 3rd hour and after copper dialysis accounted for $19.5 \%$, cramps: rate the highest rate at the 3rd hour $(20.1 \%)$, after filtration accounted for $6.5 \%$. Nausea, vomiting: only at the 3rd hour (15.6\%) and after dialysis (1.6\%), dizziness, dizziness: accounted for most at the 3rd hour (19.5\%) and after dialysis (3rd hour) ,1\%), abdominal pain, defecation: hour 1 and 2 accounted for $3.6 \%$, hour $3(3.4 \%)$, and after dialysis (3.9\%).

Keywords: Complications, cyclic dialysis, clinical, subclinical, care, counseling, patient

\section{I. ĐẶT VẤN ĐỀ}

Suy thận mạn tính (STMT) tiến triển mạn tính qua nhiêu năm tháng, măc dù khởi phát ban đầu là bệnh lý ở cầu thận, ống - kẽ thân hay mach thận, thì thông thường cũng sẽ tiến triển dần đển suy thận mạn giai đoạn cuối, lúc này hai thận mất chức năng hoàn toàn, đòi hỏi phải điều trị thay thế thận suy. Tỷ lệ mắc và mới mắc STMT ngày càng tăng trong khi điều trị thay thế mới chỉ đáp ứng xấp xỉ $10 \%$ nhu cầu [4]. Việc lọc máu chu kỳ là biện pháp tối ưu và rất hiệu quả, giúp người bệnh (NB) đào thải chất (độc) ra khỏi cơ thể do chức năng thận không đào thải được... Tuy nhiên, thận nhân tạo đi kèm với nhiều $B C$ cấp và dài ngày, trong các biến chứng cấp, tưt $\mathrm{HA}$ là $\mathrm{BC}$ thường gặp nhất, biến chứng nguy hiểm đến tính mạng như bất thường về tụt huyết áp, điện giải $(K, \mathrm{Na})$ trong quá trình lọc 
máu nếu không được theo dõi chăm sóc (TDCS) sát sao [3]. Hiệu quả điều trị đối với buổi lọc máu chu kỳ (LMCK) có thể được đánh giá bằng các dấu hiệu lâm sàng, cận lâm sàng [2]. Từ thực tế trên đề tài"Thực trạng biến chứng trong lọc máu và kết quả chăm sóc người bệnh suy thận mạn giai đoạn cuối có lọc máu chu kỳ tại bệnh viện ĐK Cà Mau" được tiến hành nhằm mục tiểu sau:

1. Xác định tỷ lệ biên chứng trong lọc máu và yêu tố liên quan

2. Đánh giá kêt quả chăm sóc người bệnh suy thận mạn giai đoạn cuối có lọc máu chu kỳ tại bệnh viện đa khoa Cà Mau

\section{II. ĐỐI TƯỚNG VÀ PHƯƠNG PHÁP NGHIÊN CỨU}

1. Đối tượng nghiên cứu: Tiêu chuẩn lựa chọn: Người bệnh được chẩn đoán bệnh STMT giai đoạn cuối đang điều trị LMCK tại bệnh viện đa khoa Cà Mau Tỉnh Cà Mau. Nghiên cứu loại trừ những NB tình trạng nặng không thể tham gia phỏng vấn, NB suy thận cấp hoặc NB không đồng ý tham gia. Thời gian: 9/2020 đến 12/2020

2. Thiết kế nghiên cứu: Nghiên cứu mô tả tiến cứu

Cỡ mẫu: Tổng số 384 người bệnh STMT giai đoạn cuối đang LMCK tại BVĐK Cà Mau

3. Phương pháp thu thập số liệu: Phỏng vấn $N B$ và sử dụng hồ sơ $B A$, từ bảng theo dõi $N B$

4. Xử lý sổ liệu: Phân tích, xử lý bằng phần mềm SPSS 20.0.

5. Biến số NC: Tuổi, giới, nghề nghiệp, nơi ở, trình độ học vấn, thời gian mắc bệnh, tmạch, huyết áp, nhiệt độ, nhịp thở, mệt mỏi, công thức máu, ure, creatinine, $\mathrm{K}$, Na; chăm sóc, tư vấn cho NB.

6. Xử lý số liệu: phân tích, xử lý bằng phần mềm SPSS 20.0 để tính tỷ lệ phần trăm, phân tích đơn biến các yếu tố liên quan có ý nghĩa thống kê khi $p<0,05$.

\section{KẾT QUẢ NGHIÊN CỨU}

\section{1. Đặc điểm chung của đôi tượng nghiên cứu}

Bảng 1. Đặc điểm chung của đôî tượng nghiên cứu

\begin{tabular}{|c|c|c|}
\hline Biến số nghiên cứu & n (384) & Tỷ lê (\%) \\
\hline Giới: & 194 & 50,5 \\
\hline Nũ & 190 & 49,5 \\
\hline \multicolumn{3}{|c|}{ Tuổi của đối tượng nghiên cứu } \\
\hline $18-35$ & 58 & 15,1 \\
\hline $36-59$ & 204 & 53,1 \\
\hline$\geq 60$ & 122 & 31,8 \\
\hline \multicolumn{3}{|l|}{ Kinh tế gia đình } \\
\hline Hộ nghèo & 324 & 84,4 \\
\hline Hộ cận nghèo & 42 & 10,9 \\
\hline Hộ khồng nghèo & 18 & 4,7 \\
\hline \multicolumn{3}{|l|}{ Bảo hiếm y tế } \\
\hline Có $80 \%$ & 18 & 4,7 \\
\hline Có 95\% & 32 & 8,3 \\
\hline Có $100 \%$ & 334 & 87,0 \\
\hline \multicolumn{3}{|l|}{ Thời gian bi bệnh } \\
\hline <3 nằm & 20 & 5,2 \\
\hline$>3$ năm & 364 & 94,8 \\
\hline
\end{tabular}

Nhận xét: Tỷ lệ nam cao hơn nữ. Chiếm tỷ lệ cao nhất ở nhóm tuổi 36-59, tiếp đến nhóm $\geq$ 60 , và tỷ lệ thấp nhất thuộc nhóm tuổi 18-35. Hầu hết là hộ nghèo chiếm $84,4 \%$, tiếp đến hộ nghèo $(10,9 \%)$, thấp nhất hộ không nghèo $(4,7 \%)$. Bảo hiếm y tế $100 \%$ chiếm cao nhất là $87 \%$, tiếp đến BHYT $95 \%$ có $8,3 \%$, tỷ lệ thấp nhất ở nhóm BHYT $80 \%$ chiếm $4,7 \%$. Hầu hết NB bị bệnh nhiều hơn 3 năm chiếm 94,8\%, dưới 3 năm chỉ có $5,2 \%$.

\section{Tỷ lệ các biến chứng trong buổi lọc máu chu kỳ của người bệnh}

\section{Bảng 2: Thực trạng các biến chứng trong buổi lọc máu chu kỳ kèm theo thời điểm}

\begin{tabular}{|c|c|c|c|c|c|c|}
\hline \multicolumn{3}{|c|}{ Biến số nghiên cứu } & \multicolumn{5}{|c|}{ Người bềnh lọc máu chu kỳ (n = 384) } \\
\cline { 3 - 7 } & & Giờ 1 & Giờ 2 & Giờ 3 & Sau lọc & Cả chu kỳ \\
\hline HA tăng & Có & $10(2,6 \%)$ & $3(0,8 \%)$ & $3(0,8 \%)$ & $2(0,52 \%)$ & $18(4,72 \%)$ \\
\hline Biến chứng tụt HA & Có & $0(0,0 \%)$ & $15(3,9 \%)$ & $80(20,8 \%)$ & $10(2,6 \%)$ & $105(27,3 \%)$ \\
\hline Tai biến hỏng FAV & Không & $384(100 \%)$ & $384(100 \%)$ & $383(99,7 \%)$ & $360(93,8 \%)$ & $359(93,5 \%)$ \\
\cline { 2 - 7 } trong lọc máu & Có & $0(0,0 \%)$ & $0(0,0 \%)$ & $1(0,3 \%)$ & $24(6,3 \%)$ & $25(6,5 \%)$ \\
\hline
\end{tabular}

Nhận xét: - Người bệnh có THA: chiếm tỷ lệ cao nhất giờ $1(2,6 \%)$, giờ thứ 2 và 3 đồng chiếm $0,8 \%$ và sau lọc chiếm $0,52 \%$. Cả chu kỳ chiếm $4,72 \%$ và không có biến chứng tăng $\mathrm{HA}(5,28 \%)$

- Có biến chứng tưt HA: chiếm tỷ lệ cao nhất vào giờ thứ $3(20,8 \%)$, tiếp đến giờ thứ $2(3,9 \%)$, giờ 1 không có $(0,0 \%)$, sau LMCK là 2,6\%. Cả chu kỳ có biến chứng tụt $\mathrm{HA}$ chiếm $27,3 \%$ và không có biến chứng tụt HẢ chiếm 72,7\%.
- Có hỏng FAV trong lọc máu chỉ chiếm 0,3 ở giờ thứ 3 và sau lọc chiếm $6,3 \%$, tính cả chu kỳ chiếm $6,5 \%$ và không gặp hỏng FAV trong lọc máu chiếm $93,5 \%$

Bảng 3. Tỷ lệ biến chứng trong buổi lọc máu chu kỳ

\begin{tabular}{|c|c|c|}
\multirow{2}{*}{ Biến số nghiên cứu } & \multicolumn{2}{|c|}{$\begin{array}{c}\text { NB bị STM lọc máu } \\
\text { chu kỳ (n= 384) }\end{array}$} \\
\cline { 2 - 3 } & Số lượng & Tỷ lệ \%
\end{tabular}




\begin{tabular}{|c|c|c|c|}
\hline Các biến chứng & Có & 142 & 37,0 \\
\cline { 2 - 4 } $\begin{array}{c}\text { trong buổi lọc } \\
\text { máu chu kỳ }\end{array}$ & Không & 242 & 63,0 \\
\hline
\end{tabular}

Nhân xét: Tỷ lệ có biễn chứng trong buổi loc máu chu kỳ chiểm $37 \%$ và không có biến chứng trong buổi lọc máu chiếm $63 \%$

Bảng 4. Biểu hiện lâm sàng khi người đã có biến chứng trong lọc máu CK

\begin{tabular}{|c|c|c|c|c|}
\hline \multirow{2}{*}{ Biến số nghiên cứu } & \multicolumn{3}{|c|}{ NB bị STM lọc máu chu kỳ (n= 384) } \\
\cline { 2 - 5 } & Giờ 1 & Giờ 2 & Giờ 3 & Sau lọc \\
\hline Da ấm lạnh, vã mồ hôi & $0(0,0 \%)$ & $15(3,9 \%)$ & $75(19,5 \%)$ & $75(19,5 \%)$ \\
\hline Chuột rút & $0(0,0 \%)$ & $17(4,4 \%)$ & $77(20,1 \%)$ & $25(6,5 \%)$ \\
\hline Buồn nôn, nôn & $0(0,0 \%)$ & $9(2,3 \%)$ & $60(15,6 \%)$ & $6(1,6 \%)$ \\
\hline Hoa mắt, chóng mặt, & $1(0,3 \%)$ & $12(3,1 \%)$ & $75(19,5 \%)$ & $12(3,1 \%)$ \\
\hline Đau bụng, đi ngoài & $14(3,6 \%)$ & $14(3,6 \%)$ & $13(3,4 \%)$ & $15(3,9 \%)$ \\
\hline
\end{tabular}

Nhân xét: - Có da ẩm lạnh, vã mồ hôi: vào giờ thứ 3 và sau lọc đồng chiếm $19,5 \%$, tiếp đến giờ thứ $2(19,5 \%)$ và giờ thứ 1 không có $(0,0 \%)$. Chuột rút: Có bị vào giờ thứ 3 chiếm $20,1 \%$, tiếp đến giờ thứ 2 chiếm $4,4 \%$, giờ $1(0,0 \%)$ và sau lọc chiếm $6,5 \%$. Có buồn nôn, nôn: giờ thứ nhất không có $(100 \%)$, giờ thứ 2 chiếm 2,3\%, giờ thứ 3 chiếm $15,6 \%$ và sau LMCK chiếm $1,6 \%$. Có hoa mắt, chóng mă̆t: giờ thứ nhất chỉ chiếm $0,3 \%$, giờ thứ 2 chiếm $3,1 \%$, giờ thứ 3 chiếm $19,5 \%$ và sau LMCK chiếm 3,1\%. Có đau bụng, đi ngoài: giờ 1 và 2 đồng chiếm $3,6 \%$, giờ 3 chiếm $3,4 \%$, và sau LMCK chiếm 3,9\%.

3. Hoạt động chăm sóc, tư vấn NB trong buổi LMCK

Bảng 5. Tỷ lệ các hoạt động chăm sóc, theo dối NB trong buổi LMCK

\begin{tabular}{|c|c|c|}
\hline \multirow[t]{2}{*}{ Biến số nghiên cứu } & \multicolumn{2}{|c|}{$\begin{array}{c}\text { Người bệnh lọc } \\
\text { máu chu kỳ }\end{array}$} \\
\hline & & \\
\hline $\begin{array}{r}\text { Động V } \\
\text { để N } \\
\end{array}$ & 309 & 80,5 \\
\hline Theo dõi vị t & 57 & \\
\hline giờ & & 98,2 \\
\hline Ĉ̂n & & 99,5 \\
\hline $\begin{array}{r}\text { TD hoą } \\
\text { đường d }\end{array}$ & 374 & 97 \\
\hline $\begin{array}{r}\text { TD nguy c } \\
\text { xữ tr } \\
\end{array}$ & 3 & 98 \\
\hline $\begin{array}{c}\text { TD dịch, thuốc đưa vào NB } \\
\text { trong LMCK }\end{array}$ & 3 & 97 \\
\hline $\begin{array}{c}\text { Theo dõi tốc độ, thời gian } \\
\text { lọc máu }\end{array}$ & 368 & \\
\hline
\end{tabular}

Nhận xét: Có động viên người bệnh yên tâm chiếm $80,5 \%$.. Có TD vị trí chích kim hiếm $93 \%$. Có TD dôi dấu sinh tồn/mỗi giờ dõi dấu sinh tồn/mỗi giờ chiếm 98,2\%. Có cân NB trước và sau lọc máu chiếm 99,5\%. Có TD hoạt động máy, đường dây dẫn truyền chiếm 97,4\%. Có TD biến chứng xãy ra, xử trí kịp thời chiếm 98,7\%. Có TD dịch, các loại thuốc đưa vào NB (TYL) chiếm 97,4\%. Có TD tốc độ, thời gian lọc máu chiếm 95,8\%.

Bảng 6. Tỷ lệ tư vân, giáo dục sức khỏe NB tư vấn cho NB trong buổi $L M C K$

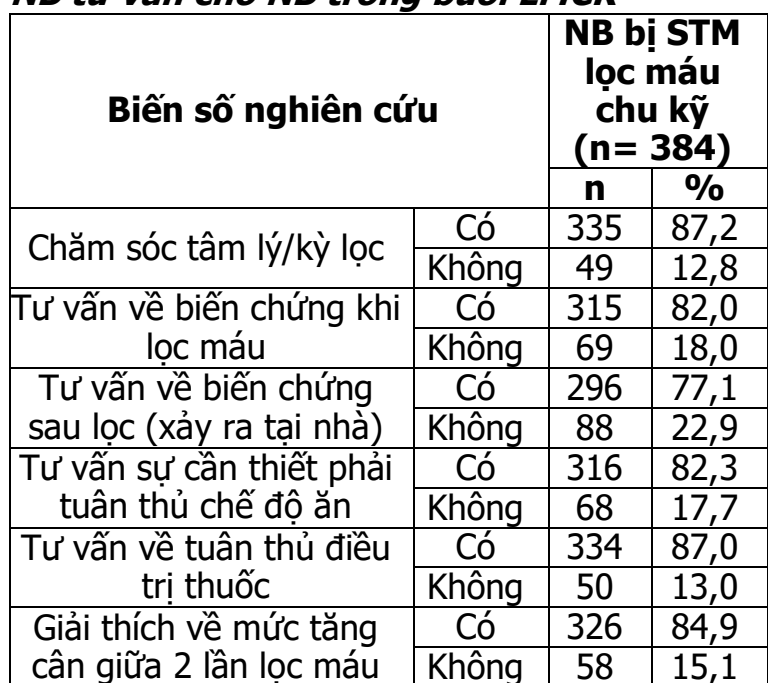

Nhận xét: Kết quả cho thấy, có CS tâm lý/kỳ lọc chiếm $87,2 \%$ và không TH là $12,8 \%$. Có tư vấn về biến chứng khi loc máu chiếm $82 \%$ và không $\mathrm{TH}$ là $18 \%$. Có TV về biến chứng sau lọc (xảy ra tại nhà chiếm $77,1 \%$ và không $\mathrm{TH}$ chiếm $22,9 \%$. Có về tuân thủ chế độ ăn chiếm $82,3 \%$ và không tư vấn chiếm $13 \%$. Có giải thích về mức tăng cân giữa 2 lần lọc máu chiếm 84,9\% và không giải thích chiếm 15,1\%.

Bảng 7. Đánh giá kết quả chăm sóc chung đôî tượng nghiên cứu

\begin{tabular}{|c|c|c|c|c|}
\hline \multirow{2}{*}{ Biến số nghiên cứu } & \multicolumn{2}{|c|}{$\begin{array}{c}\text { CS mớc } \\
\text { tốt }\end{array}$} & \multicolumn{2}{|c|}{$\begin{array}{c}\text { CS maúc } \\
\text { khá }\end{array}$} \\
\cline { 2 - 5 } & $\mathbf{n}$ & $\mathbf{N}$ & $\mathbf{\%}$ \\
\hline Hoạt động tư vấn & 312 & 81,3 & 72 & 18,7 \\
\hline $\begin{array}{c}\text { Hoạt động TD chăm } \\
\text { sóc }\end{array}$ & 356 & 92,7 & 28 & 7,3 \\
\hline $\begin{array}{c}\text { Kết quả chăm sóc } \\
\text { chung (CS và tư vấn) }\end{array}$ & 292 & 76,0 & 92 & 24,0 \\
\hline
\end{tabular}

Nhận xét: Bảng trên cho thấy, Kết quả chăm sóc NB trong LMCK ở mức tốt chiếm $92,7 \%$ và mức khá chiếm $7,3 \%$. Kết quả tư vấn mức tốt 
chiếm $81,3 \%$ và mức chưa tốt chiếm 18,7\%. Kết quả chăm sóc chung (cả CS và tư vấn) ở mức tốt chiếm $76 \%$ và mức khác chiếm $24 \%$

\section{Một số yêu tố liên quan}

Bảng 8. Sự liên quan giữa đặc điểm người bệnh với biến chứng trong loc máu

\begin{tabular}{|c|c|c|c|c|c|}
\hline \multirow{2}{*}{\multicolumn{2}{|c|}{ Biến số nghiên cứu }} & \multicolumn{2}{|c|}{ NB bị STM lọc máu CK(n= 384) } & \multirow[b]{2}{*}{ OR } & \multirow{2}{*}{$\mathbf{P}$} \\
\hline & & Có biến chứng & Không có biến chứng & & \\
\hline \multirow{2}{*}{ Giới } & Nam & $78(40,2 \%)$ & $116(59,8 \%)$ & \multirow{2}{*}{1,324} & \multirow{2}{*}{0,186} \\
\hline & Nữ & $64(33,7 \%)$ & $126(66,3 \%)$ & & \\
\hline \multirow{2}{*}{ Tuổi } & $>60$ tuối & $54(44,3 \%)$ & $68(55,7 \%)$ & \multirow{2}{*}{1,570} & \multirow{2}{*}{0,05} \\
\hline & $<60$ & $88(33,6 \%)$ & $174(66,4 \%)$ & & \\
\hline \multirow{2}{*}{ Hộ gia đình } & Hộ cận nghèo & $25(59,5 \%)$ & $17(40,5 \%)$ & \multirow{2}{*}{2,82} & \multirow{2}{*}{0,001} \\
\hline & Hộ nghèo & $111(34,3 \%)$ & $213(65,7 \%)$ & & \\
\hline \multirow{2}{*}{$\begin{array}{c}\text { Tăng cân } \\
\text { giữa } 2 \text { kỳ lọc }\end{array}$} & $>5 \%$ & $138(38,5 \%)$ & $220(61,5 \%)$ & \multirow[t]{2}{*}{3,450} & \multirow{2}{*}{0,020} \\
\hline & $\leq 5 \%$ & $4(15,4 \%)$ & $22(84,6 \%)$ & & \\
\hline \multirow{2}{*}{ Tư vấn } & Chưa tốt & $38(52,8 \%)$ & $34(47,2 \%)$ & \multirow[t]{2}{*}{2,235} & \multirow{2}{*}{0,002} \\
\hline & Tốt & $104(33,3 \%)$ & $208(66,7 \%)$ & & \\
\hline \multirow{2}{*}{ Chăm sóc } & Chưa tốt & $19(67,9 \%)$ & $9(32,1 \%)$ & \multirow[t]{2}{*}{3,999} & \multirow{2}{*}{0,001} \\
\hline & Tốt & $123(34,6 \%)$ & $233(65,4 \%)$ & & \\
\hline
\end{tabular}

Nhận xét: Kết quả cho thấy, chưa tìm thấy sự khác biệt giữa nam và nữ với biến chứng trong LMCK. Có sự khác biệt và có ý nghĩa thống kê giữa NB có nhóm tuổi $>60$ tuổi và $<60$ tuổi với $\mathrm{p}<0,05$. Có sự khác biệt giữa NB có hộ cận nghèo và hộ nghèo với $\mathrm{p}<0,001$. Có sự khác biệt và có ý nghĩa thống kê giữa tăng cân giữa 2 lần lọc $>5 \%$ và $\leq 5 \%(p<0,02)$. Có sự khác biêtt và có ý nghĩa thống kê giữa $\mathrm{NB}$ được tư vấn tốt và $N B$ chưa được tư vấn tốt với $p<0,002$. Và có sự khác biệt giữa NB được chăm sóc tốt và và NB chưa được chăm sóc tốt với $p<0,002$.

\section{BÀN LUÂ̂N}

\section{1. Đặc điểm của đối tượng nghiên cứu:}

Tỷ lệ nam cao hơn nữ (50,5\% so với 49,5\%), và kết quả này cũng tương dồng với Nguyên Thị Hăng tại BVĐK Kiến Giang năm 2019, có $(54,8 \%$ so với 46,2\%)[1]. Về tuổi, chiếm tỷ lệ cao nhất ở nhóm tuổi $<60$ tuổi chiếm $68,2 \%$, kết quả này thấp hơn KQNC của Đố Lan Phương năm 2015 tại bênh viên Bach Mai là 78,4\%. Tiếp đến nhóm $\geq 60$ tuổi chiếm $31,8 \%$ lại cao hơn kết quả nghiên cứu của Đỗ Lan Phưởng $(21,6 \%)$ và cũng cao hơn kết quả nghiên cứu của Nguyễn Thị Hằng $(22,3 \%)[4]$. Hầu hết là hộ nghèo chiếm $84,4 \%$, tiếp đến hộ cận nghèo $(10,9 \%)$, thấp nhất hộ không nghèo $(4,7 \%)$, kết quả nghiên cứu của chúng tôi cũng thương đồng với kết quả của nguyễn Thị Hằng có hộ nghèo chiếm tỷ lệ cao hơn cao nhất $(51,2 \%)$ và thấp nhất là hổ câan nghèo $(23,7 \%)$ [1]. Về bảo hiểm y tế $100 \%$ chiếm cao nhất $87 \%$, tiếp đến BHYT $95 \%$ có $8,3 \%$, tỷ lê thấp nhất ở nhóm BHYT $80 \%$ chiếm $4,7 \%$; tỷ lệ này cũng tương đồng Nguyễn Thị Hằng đó là $100 \% \mathrm{NB}$ có sử dụng $\mathrm{BHYT}$, nhưng chỉ có hơn $60 \%$ NB hưởng mức BH $100 \%$ thấp hơn KQNC của chúng tôi ( $60 \%$ so với $87 \%$ ). Kết quả NC của chúng tôi hầu hết NB bị bệnh trên 3 năm chiếm $94,8 \%$, dưới 3 năm chỉ có $5,2 \%$ [1]

2. Các biến chứng biểu hiện trong buổi lọc máu chu kỳ kèm theo thời điểm

- Người bệnh có THA: chiếm tỷ lệ cao nhất giờ $1(2,6 \%)$, giờ thứ 2 và 3 đồng chiếm $0,8 \%$ và sau lọc chiếm $0,52 \%$. và không có biến chứng tăng $\mathrm{HA}(5,28 \%)$, kết quả nghiên cứu của chúng tôi tính cả chu kỳ chỉ chiếm $4,72 \%$ cũng vẫn thấp hơn nghiên cứu của Nguyến Thị Hằng, NB có tăng HA chiếm tới 7,9\% [1]

- Có biến chứng tưt HA: kết quả nghiên cứu của chúng tôi cho thấy tỷ lệ biến chứng tự $\mathrm{HA}$ đều thấp hơn của Đố Lan Phương (2015) như vào giờ thứ nhất giờ 1 chúng tôi không nghi nhân $\mathrm{BN}$ nào bị tụt $\mathrm{HA}(0,0 \%)$ giờ thứ $2(3,9 \%)$ thấp hơn 6,5 lần so với của Đố Lan Phương $(3,9$ so với $25,6 \%$ ) và vào giờ thứ 3 nghiên cứu của của chúng tôi có tỷ lệ tụt HA là 20,8\%, kết quả này thấp bằng nửa so với tỷ lệ tụt $\mathrm{HA}$ trong buổi lọc máu của Đố Lan Phương (2015) vào giờ thứ 3 chiếm $43,6 \%$. Nói về tỷ lệ sau lọc có tụ HA của Đố Lan Phương có $7,7 \%$, tỷ lệ này cao gấp 2,96 lần so với KQNC về sau LMCK của chúng tôi là 2,6\%. KQNC của chúng tôi cho thây, cả chu kỳ có biến chứng tụt $\mathrm{HA}$ chiếm $27,3 \%$ và không có biến chứng tự HA chiếm $72,7 \%$ có thể giải thích cho điều này là bệnh viện ĐK Cà Mau mặc dù là vùng đất tận cùng của tổ quốc nhưng chúng tôi thực hiện chăm sóc người bệnh toàn diện theo chỉ đạo của Bộ Y tế do vậy tỷ lệ tụt HA trong buổi L̇M thấp hợn của Đỗ Lan Phương (27,3\% so với $35,1 \%$ ) [4]. Về có hỏng FAV trong lọc máu chỉ chiếm 0,3 ở giờ thứ 3 và sau lọc chiếm 6,3\%. Theo NC của Nguyễn Thị Hằng có tỷ lệ hỏng 
FAV trong lọc máu chiếm 15,3\% cao gấp 2,35 lần so với KQNC của chúng tôi, tính cả chu kỳ có hỏng FAV trong lọc máu chiếm 6,5\% [1]

Tỷ lệ có các biến chứng trong buổi lọc máu chu kỳ: là $37 \%$ và không có biến chứng là $63 \%$, tỷ lệ này cao hơn của Đổ Lan Phương [4]

3. Biểu hiện lâm sàng khi người đã có biến chứng trong lọc máu CK: theo nghiên cứu của Đô̂ Lan Phương có biểu hiên da ẩm lanh, vã mồ hôi trong buổi lọc máu chiếm $41 \%$, KQNC này cao gấp hơn 2 lần so với KQNC của chúng tôi: như da ẩm lạnh, vã mồ hôi: vào giờ thứ 3 và sau lọc đồng chiếm 19,5\%, tiếp đến giờ thứ 2 $(19,5 \%)$ và giờ thứ 1 không có $(0,0 \%)$. Về chuột rút, Đỗ Lan Phương có biểu hiện chuột rút chiếm $17,9 \%$ và tỷ lệ này thấp hơn KQNC của chúng tôi ở giờ thứ 3 lại chiếm $20,1 \%$, nhưng lại cao hơn rất nhiêu ở giờ thứ 2 của chúng tôi chỉ $4,4 \%$, giờ $1(0,0 \%)$ và sau lọc chiếm $6,5 \%$. Nghiên cứu của Đố Lan Phương có biểu hiện buồn nôn, nôn hiếm $17,9 \%$, tỷ lê này cao hơn nhiều so với KQNC của chúng tôi và có hoa mắt, chóng mặt cũng cao hơn KQNC của chúng tôi, như giờ thứ 3 của chúng tôi là 19,5\%, của Đố Lan Phương lại là $20,6 \%$. Nhưng có đau bụng, đi ngoài: KQNC của chúng tôi lại cao hơn của Đỗ Lan Phương chỉ chiếm $2,6 \%$ mà của chúng tôi là giờ thứ nhất và 1 đống chiếm $3,6 \%$, giờ thứ 3 chiếm $3,4 \%$, và sau LMCK chiếm 3,9\% [4], [3]

4. Vê các hoạt động chăm sóc, theo dõi NB trong buổi LMCK: Các nội dung NB được theo dõi chăm sóc như động viền $(80,5 \%)$, TD vị trí chích kim (93\%). TD mỗi giờ TD dấu sinh $(98,2 \%)$, cân NB (99,5\%). TD hoạt động máy $(97,4 \%)$, xử trí kịp thời biến chứng $(98,7 \%)$. TD dịch, thuốc đưa vào NB $(97,4 \%)$. TD tốc độ, thời gian lọc máu $(95,8 \%)$. Kết quả của chúng tôi đã cho thấy hâuu hết chiếm tỷ lệ cao từ $80,5 \%$ đến $99,5 \%, K Q$ của của chúng tồi cao gấp gần 2 lần so với KQNC của Nguyễn Thị Hằng tại $\mathrm{BV}$ Kiên Giang có chăm sóc mức tốt là 41,5 và mức chưa tốt là $58,5 \%$, và lại càng cao hơn rất nhiều về nội dung TDCS biến chứng so với KQNC của Đỗ Lan Phương NB được TD các biến chứng trong buổi lọc máu giờ thứ nhất chiếm $23,1 \%$, giờ thứ 2 chiếm $25,6 \%$ và giờ thứ 3 chiếm $43,6 \%$ và sau lọc chỉ có $7,7 \%[1]$, [4], [5]

5. Vê Hoạt động tư vấn, giáo dục sức khỏe: Kết quả NC của chúng tôi có CS tâm lý/kỳ lọc chiếm $87,2 \%$ và không TH là $12,8 \%$. Có tư vấn về biến chứng khi lọc máu chiếm $82 \%$ và không TH là $18 \%$. Có tư vấn về biến chứng sau loc (xảy ra tại nhà chiếm $77,1 \%$ và không $T H$ chiếm $22,9 \%$. Có về tuân thủ chế độ ăn chiếm
$82,3 \%$ và không tư vấn chiếm $13 \%$. Có giải thích về mức tăng cân giữa 2 lần lọc máu chiếm $84,9 \%$ và không giải thích chiếm $15,1 \%$.

6. Một số yếu tố liên quan đến biến chứng trong buổi LMCK: Kết quả cho thấy, chưa tìm thây sự khác biệt giữa nam và nữ với biến chứng trong LMCK., KQNC của chúng tôi lại trái ngược với Nguyễn Thị Hằng là có sự khác biệt và có ý nghĩa thống kê giữa nam và nữ ( $p$ $>0,05)$, và lai chưa tìm thây sự khác biệt giữa các nhóm tuổi; hộ cận nghèo và Hộ nghèo $\mathrm{p}>$ 0,05 [1]. Kết quả cho thây, có sự khác biệt và có ý nghĩa thống kê giữa Tăng cân giữa 2 lần lọc > $5 \%$ và $\leq 5 \%(p<0,02)$, kết quả này cũng tương đồng với Nguyễn Thị Hằng tại bệnh viện ĐK Kiên Giang cũng có sự khác biệt $(p<0,014)$. Về sự liên quan đến Kết quả cho thấy, có sự khác biệt và có ý nghĩa thống kê giữa NB được tư vấn tốt và $N B$ chưa được tư vấn tốt với $p<0,002$, giải thích cho điều này có thể nói khi NB được tư vấn kỹ các nội dung liên quan đến buổi LMCK để họ có kiến thức và phòng tránh các biến chứng nếu có. Nhưng nếu NB chưa được tư vấn tốt có nghĩa là họ vẫn còn thiếu hụt kiến thức về buổi LMCK thì nguy cơ biến chứng xuất hiện học cũng không hiểu biết, do vậy có sự liền quan giữa trước và sau buối lọc cũng là điểu dễ hiểu. Và có sự khác biệt và có ý nghĩa thống kê giữa NB được chăm sóc tốt trong buổi loc máu chu lỳ và và NB chưa được chăm sóc tốt trong buổi LMCK với $p<0,002$, kết quả nghiên cứu của chúng tôi lại trái ngược với Nguyễn Thị Hằng chưa tìm thây được sự liên quan giữa NB trong buổi LMCK với mức độ chăm sóc có lẽ do cõ̃ mẫu còn chưa đủ lớn để tìm thấy sự khác biệt này $(p>0,05)[1]$, [6].

\section{KẾT LUÂNN}

1. Tỷ lệ biến chứng trong lọc máu là: Có biến chứng là $37 \%$ và không có biến chứng là $63 \%$

2. Một số yếu tố liên quan: Có sự liên quan giữa NB có nhóm tuổi $>60$ tuổi và $<60$ tuổi $(p<0,05)$. Có sự khác biệt giữa hộ cận nghèo và hộ nghèo $(p<0,001)$. Có sự khác biệt và có ý nghĩa thống kê giữa Tăng cân giữa 2 lần lọc $>$ $5 \%$ và $\leq 5 \%(p<0,020)$. Có sự liên quan giữa $\mathrm{NB}$ được tư vấn tốt và NB chưa được tư vấn tốt $(p<0,002)$. Và có sự khác biệt và có ý nghĩa thống kê giữa NB được chăm sóc tốt và và $N B$ chưa được chăm sóc tốt với $p<0,002$.

3. Kểt quả chăm sóc người bệnh suy thận mạn giai đoạn cuối có lọc máu chu kỳ: Kết quả chăm sóc NB trong LMCK ở mức tốt chiếm $92,7 \%$ và mức khá chiếm $7,3 \%$. Kết quả tư vấn mức tốt chiếm $81,3 \%$ và mức chưa tốt chiếm 
$18,7 \%$. Kết quả chăm sóc chung (cả CS và tư vấn): ở mức tốt chiếm $76 \%$ và mức khá chiếm $24 \%$.

\section{TÀI LIÊU THAM KHẢO}

1. Nguyễn Thị Hằng (2020), Kết quả chăm sóc người bệnh loc máu chu kỳ và mô̂t số yếu tố liên quan tại khoa Thận lọc máu Bệnh viện đa khoa Kiên Giang. Luận văn thạc sĩ điểu dưỡng, Trường đai hoc Thăng Long, năm 2020.

2. Đố Thị Hiến và CS (2020), Đánh giá sự tuân thủ điều trị ở bệnh nhân tang huyết áp được điều trị ngoại trú tại Phòng khám Nội Tim mạch - Bệnh viện Trung ương Quân đội 108, Tap chí Y Dược lâm sàng 108, Hội nghị KH điều dưỡng bệnh viện 2020, tập 15, 11/2020

3. Trân Thị Thùy Nhi và CS (2017), Nghiên cứu tuân thủ sử dụng thuốc theo thang điêm Mirisky (VMAS -8 ) và hiệu quả tư vấn trên bệnh nhân đái tháo đường típ 2. Hội Nội tiết và Đái tháo đường miền trung, 17/3/2021. Chuyên đề, đái tháo đường, tap chí số $46+47$

4. Đố Lan Phương (2015), "Biến chứng tưt huyết áp trong buổi loc máu chu kỳ ở bênh nhân suy thận mạn tính giai đoạn cuối tại khoa thận nhân tạo - bểnh biện Bạch Mai", đề tải nghiên cứu khoa hoc cấp cơ sở, bênh viên Bach Mai, năm 2015

5. Bùi Minh Thông và CS (2018), Thực trạng công tác giáo duc sức khỏe cho người bềnh tai bênh viện Nội tiết trung ương năm 2018. Kỷ yếu Hội nghị khoa học bệnh viện Nội Tiết trung ương mở rộng năm 2019. Tr 349 - 355 .

6. Trân Thị Thanh Thảo và CS (2020), Thực trang kỹ năng giáo tiếp, ứng xữ với bênh nhân của điêu dưỡng Khoa Khám bệnh Cán bộ cao cấp, Bệnh viện Trung ương Quân đội 108 nẳm 2020. Tap chí Y Dược lâm sàng 108, tập 15, số đặc biệt 11/2020

\section{ĐĂC ĐIỂM LÂM SÀNG, CÂN LÂM SÀNG VÀ KÊT QUẢ ĐIỀU TRI U XO' TỬ CUNG BẰNG PHẪU THUÂTT TẠI BÊ̂NH VIỆN ĐA KHOA TİNH TUYÊN QUANG}

\section{TÓM TẮT}

Bệnh viện đa khoa tỉnh Tuyên Quang đã triển khai nhiều phưởng pháp phấu thuật mới điều trị $u$ xơ tử cung nên cần phải có tổng kết và rút kinh nghiệm. Mục tiêu nghiên cứu: (1)Mô tả đặc điểm lậm sàng và cận lâm sàng trên bệnh nhân được phẫu thuật UXTC tai bênh viên Đa khoa tỉnh Tuyển Quang năm 2019 - 2020; (2) Nhận xét kết quả xử trí UXTC bằng phẫu thuât ở nhóm bênh nhân trên. Đối tượng và phương pháp nghiên cứu: mô tả cắt ngang 189 bệnh nhân đước chẩn đoán xác định là u xơ tử cung được phẫu thuật tại bệnh viện đa khoa tỉnh Tuyên Quang từ tháng 1 năm 2019 đến tháng 12 năm 2020. Kết quả nghiên cứu: Tuổi trung bình của đối tượng nghiên cứu là 41,8 8 3,8 tuổi, thấp nhất là 37 tuổi, cao nhất là 59 tuối. Có tới $16,4 \%$ bệnh nhân có trình độ học vấn từ cấp 1 trở xuống. Có tới hơn $50 \%$ bệnh nhần có thời gian phát hiện $u$ xớ trên 1 năm. Triệu chứng hay gặp nhất là đau bụng tức hạ vị, ra máu âm đạo, rối loạn tiểu tiện với tỉ lệ lần lượt là 93,7\%, 49,7 và $38,6 \%$. Có 11 bệnh nhân được phấu thuật nội soi chiếm $5,8 \%$ và 178 bệnh nhân được phẫu thuật mổ mở chiếm $94,2 \%$. Trong đó phẫu thuật chủ yếu lì bóc u xơ tử cung 26,9\%; cắt tử cung bán phân 34,4 ) và cắt tử cung hoàn toàn là $38,7 \%$. Có $51,9 \%$ để lại hai phần phụ, $35,4 \%$ cắt hai phần phụ và $12,7 \%$ cắt một

\footnotetext{
${ }^{1}$ Bệnh viện đa khoa tỉnh Tuyên Quang

Bộ môn Phụ Sản, Đại học Y Hà nội

Chịu trách nhiệm chính: Phùng Trọng Thủy

Email: trongthuytq2012@gmail.com

Ngày nhận bài: 14.5.2021

Ngày phản biên khoa họ: 5.7.2021

Ngày duyệt bài: 16.7.2021
}

\section{Phùng Trọng Thủy ${ }^{1}$, Phạm Bá Nha²}

phần phụ. Chỉ có 4 bệnh nhân nhiễm trùng mỏm cắt chiếm $2,1 \%$ và 1 bệnh nhân tổn thương tang chiếm 0,5\%. Cần chú trọng việc khám, đánh giá tình trạng bệnh nhân, và các yếu tố liên quan để lựa chọn phương pháp phẫu thuật phù hợp.

Tư khóa: u xơ tử cung, phẫu thuật, bệnh viện đa khoa tỉnh Tuyên Quang.

\section{SUMMARY}

\section{CLINICAL, SUB-CLINICAL AND OUTCOME TREATMENT METROFIBROMA BY SURGERY IN TUYEN QUANG PROVINCE GENERAL HOSPITAL}

Tuyen Quang province general hospital has conducted new surgery methods to treat metrofibroma so need summary for experience. Purposes: (1) Describe the clinical and sub-clinical treatment metrofibroma by surgery patients in Tuyen Quang province general hospital 2019 - 2020; (2) Review the outcome of treatment. Subject and Method: cross sectional study on 189 patient diagnosed metrofibroma and surgery in Tuyen Quang province general hospital from Jan 2019 to Dec 2020. Results: Average age was $41.8 \pm 3.8$ (min $37-\max$ 59). $16.4 \%$ patients have primary school degree. $50 \%$ patients have duration of suffering from metrofibroma over one year. Comment symptoms: pelvic pain, bleeding, abnormal urinary were $93.7 \%, 49.7$ and $38.6 \%$, respectively. $11(5.8 \%)$ patients reveived laparoscopy and 178 (94.2\%) received open surgery. Percentage of hysteroscopic myomectomy, partial hysterectomy, total hysterectomy were $26.9 \%$; $34.4 \%$ and $38.7 \%$. Percentage of ovarian conservation, one or two ovarian removal patients were $51.9 \%$; $35.4 \%$ and $12.7 \%$, respectively. Only 4 patients $(2.1 \%)$ suffered from infection and $0.5 \%$ suffered from organ 